\title{
Reconstituição da válvula ileocecal em cães ${ }^{1}$
}

\author{
Ileocecal valve reconstruction in dogs
}

\section{Felipe Antonio Boff Maegawa² ${ }^{2}$, José Antônio de Souza ${ }^{3}$, Edevard José de Araújo ${ }^{3}$, Ivan Hong Jun $\mathrm{Koh}^{4}$, Armando José d'Acampora ${ }^{5}$, Débora Cadore de Farias ${ }^{6}$, Jackson Mengarda ${ }^{6}$, Daniel Volpato ${ }^{6}$, Luis Gustavo Ferreira da Silva ${ }^{2}$, Cleta Selva de Córdova ${ }^{7}$}

\author{
1 Trabalho realizado na Disciplina de Técnica Operatória e Cirurgia Experimental da Universidade Federal de Santa \\ Catarina (UFSC). \\ 2. Médico Residente, Hospital Universitário - Universidade Federal de Santa Catarina (HU-UFSC). \\ 3. Professor Adjunto Doutor de Cirurgia Pediátrica da UFSC. \\ 4. Professor Livre-Docente da Disciplina de Técnica Operatória e Cirurgia Experimental pela Universidade Federal de \\ São Paulo - Escola Paulista de Medicina (UNIFESP-EPM). \\ 5. Professor Adjunto Doutor de Técnica Operatória e Cirurgia Experimental da UFSC. \\ 6. Aluno da Graduação em Medicina da UFSC. \\ 7. Bioquímica do HU-UFSC.
}

\section{RESUMO}

Objetivo: Avaliar uma técnica de reconstituição da válvula ileocecal com base em técnicas anti-refluxo vesicoureteral. Métodos: Quatorze beagles foram operados. Em sete foi reconstituída a válvula ileocecal com a técnica proposta e nos outros sete realizou-se apenas a anastomose ileocólica término-terminal. Para avaliar a neoválvula realizou-se o acompanhamento clínico dos cães, a análise microbiológica e o estudo manométrico. Resultados: Clinicamente, durante os 45 dias de pós-operatório, não houve diferença entre os cães com e sem reconstituição da válvula ileocecal. Na análise de bactérias aeróbias, a bactéria predominante foi a Escherichia coli. Quantitativamente, as culturas cresceram de modo irregular, não permitindo a comparação do crescimento bacteriano entre os grupos com e sem válvula ileocecal. A neoválvula apresentou uma pressão de refluxo ileocólica semelhante a da válvula ileocecal fisiológica (P>0,05). Em relação ao grupo sem válvula, as pressões de refluxo da válvula fisiológica e da neoválvula foram significantemente maiores, sendo $\mathrm{P}<0,05$ e $\mathrm{P}<0,001$, respectivamente. Conclusão: Aneoválvula ileocecal serviu de obstáculo ao refluxo colo-ileal de maneira semelhante à válvula ileocecal fisiológica.

Descritores: Cirurgia. Valva ileocecal. Manometria. Cães

\begin{abstract}
Purpose: The importance of keeping the ileocecal valve in the intestinal ressections has been reported by several authors. When preserved, the ileocecal valve was related to a longer survival and prevention of the short bowel syndrome, due to its ability to block the colonic content reflux into the ileum and to avoid the rapid empting of the ileal content into the cecum. It was assessed a tecnique of ileocecal valve reconstitution, based on vesicoureteral anti-reflux tecniques. Methods: Fourteen beagles were operated. Seven underwent ileocecal valve reconstitution following the tecnique proposed and in the other seven a simple end-to-end anastomosis was performed. To assess the new valve, it was done the clinical follow up, the microbiologic analysis and the manometric study. Results: Clinically, during 45 days of follow up, there was no difference between the dogs with and without ileocecal reconstitution. In the aerobic bacteria analysis, the predominant bacterium was Escherichia coli. Quantitatively, the cultures grew in an irregular way, so that it was not able to compare the bacterial growth between the groups with or without ileocecal valve. The new valve had a
\end{abstract}


colo-ileal reflux pressure similar to that of the physiological valve $(\mathrm{P}>0.05)$. However, when compared to the non valve group, the reflux pressures of the physiological valve and new valve were significantly higher, with $\mathrm{P}<0.05$ and $\mathrm{P}<0.001$, respectively. Conclusion: In this study, the reconstituted ileocecal valve served as a barrier to the colo-ileal reflux just as the physiological valve does.

Key words: Surgery. Ileocecal Valve. Manometry. Dogs.

\section{Introdução}

A válvula ileocecal(VIC) foi descrita como tendo duas funções fisiológicas principais: $\left.1^{\mathrm{a}}\right)$ Evitar o esvaziamento rápido do conteúdo do íleo para o ceco, permitindo melhor digestão e absorção de nutrientes; $2^{\mathrm{a}}$ )Prevenir o refluxo do conteúdo colônico, com um grande número de bactérias (principalmente anaeróbias) e de produtos tóxicos da putrefação, para o íleo ${ }^{1,2,3}$. Essas funções têm sido demonstradas pela extrema distensão e, às vezes, ruptura, do cólon direito nas obstruções do intestino grosso, onde a VIC impede a descompressão retrógrada para o íleo ${ }^{4}$, bem como por estudos experimentais e clínicos ${ }^{3,5,6,7,8}$.

Rendleman e col. ${ }^{3}$, estudando a VIC em humanos, verificaram que $36 \%$ dos pacientes apresentaram refluxo colo-ileal quando submetidos a uma pressão de $25 \mathrm{~cm}$ de água no íleo terminal. Com isso, esses autores questionaram se esse refluxo realmente era patológico. Gazet e Kopp ${ }^{6}$, estudando a VIC em cães, macacos e gatos, demonstraram que a perda ponderal após sua ressecção era similar à perda após uma hemicolectomia direita clássica. Além disso, esses autores verificaram um aumento (qualitativo ou quantitativo?)da flora bacteriana no íleo terminal, naqueles animais sem VIC. Com esses resultados, esses autores sugeriram que a VIC deveria ser, sempre que possível, preservada nas cirurgias colônicas. Kholoussy e col. ${ }^{7}$ assim como Richardson e Griffen ${ }^{8}$, estudando substitutos da VIC em cães, sugeriram um papel importante na prevenção do aumento da proliferação bacteriana no íleo terminal, servindo, portanto, como uma barreira bacteriológica, além de aumentar o tempo do trânsito intestinal.

Dentre as principais causas de ressecção intestinal têm sido referidas: o trauma abdominal, a isquemia mesentérica, as enterites regionais, as obstruções seguidas de infarto intestinal, carcinoma e enteropatia por irradiação $0^{9}$. Entre os recémnascidos as causas mais comuns são as malformações congênitas do trato gastrintestinal e a enterocolite necrosante ${ }^{10}$.
Considerando as duas principais funções da VIC, prolongar o tempo do trânsito intestinal e evitar o refluxo colo-ileal, tem sido sugerido que a ressecção da VIC em alguns pacientes pode agravar ou induzir à diarréia ou sintomas semelhantes à sindrome do intestino curto ${ }^{5}$. Pacientes submetidos a ressecções intestinais extensas ou à irradiação prévia apresentam maior risco ${ }^{5}$. Clinicamente, a malabsorção e a desnutrição têm sido descritas como as principais conseqüências dessa síndrome, causando profundos distúrbios metabólicos e perda de peso ${ }^{11}$.

Essas complicações têm sido atribuídas não apenas à diminuição da absorção de sais biliares, gordura e vitaminas, causadas pela redução da área de absorção intestinal e pelo aumento do trânsito intestinal, mas também pela colonização do íleo terminal por microorganismos do cólon, o que leva à desconjugação dos sais biliares, e concomitante prejuízo da absorção de ácidos graxos ${ }^{9,12,13}$. Além disso, a presença desses ácidos graxos, bem como de sais biliares não absorvidos no cólon, interferem com a absorção colônica de sódio e água, levando a uma diarréia grave ${ }^{9}$.

Várias técnicas cirúrgicas têm sido propostas para evitar a síndrome do intestino curto, quando a VIC é ressecada. Procedimentos como a interposição antiperistáltica de segmentos intestinais ${ }^{8}$, a intussuscepção ${ }^{1,12-14}$, miectomia da parede intestinal ${ }^{15,16}$ e reconstrução da VIC ${ }^{5,11}$ são alguns deles.

Fisch e col. ${ }^{5}$ e Vinograd e col. ${ }^{11}$ propuseram um modelo de reconstituição da VIC, com base no mecanismo valvular utilizado no reimplante ureteral na bexiga com a finalidade de prevenir o refluxo vésico-ureteral.Os resultados relatados por estes influenciaram essa pesquisa, a qual se propõe verificar o papel da neoválvula ileocecal em impedir o refluxo colo-ileal.

\section{Métodos}

Foram utilizados 14 cães da raça Beagle, 
machos, pesando entre 8 e $10 \mathrm{~kg}$-, provenientes do Biotério Central da UFSC, criados exclusivamente para experimentação e identificados com tatuagens de números e letras nas orelhas. Esses cães foram distribuídos, aleatoriamente, em 3 grupos.

Grupo A (Controle): $\mathrm{n}=14$. Animais, aparentemente normais, nos quais no momento da $1^{\mathrm{a}}$ operação foi realizada coleta de amostras do conteúdo intestinal do íleo e do cólon para cultura. Em8desses animais foi medida a pressão intraluminal do cólon, capaz de causar refluxo para o íleo (pressão de refluxo colo-ileal), que serviu como parâmetro de normalidade. Após esses procedimentos os animais foram distribuídos, por sorteio, nos grupos $\mathrm{B}$ e C.

Grupo B (Neoválvula): $\mathrm{n}=7$. Animais nos quais foi construído um modelo padronizado, de substituição da VIC (neoválvula).

Grupo C (Anastomose): $n=7$. Animais nos quais foi realizada uma anastomose ileo-cólica términoterminal.

No pós-operatório imediato, após recuperação anestésica, os animais foram transferidos para o setor de pós-operatório do Biotério da UFSC, onde foram mantidos em ambiente aquecido, com auxílio de um aquecedor elétrico, em canil individual, medindo aproximadamente $1,30 \mathrm{~m}^{2}$.

No primeiro dia de pós-operatório, os animais foram confinados em área cercada (50\% tela e 50\% concreto), com piso de cimento liso, com solário, lavado diariamente, com dimensão proporcional de $1 \mathrm{~m}^{2}$ por animal. Foram mantidos em grupos de no máximo 6 animais por compartimento, sob luz natural e em temperatura ambiente.

Estes animais receberam alimentação própria para espécie, com livre acesso à dieta e água durante o experimento, exceto nas 24 horas antes do procedimento operatório. Aalimentação foi reiniciada no $1^{\circ}$ dia de pós-operatório.

A indução anestésica foi realizada após um período de jejum de 24 horas. Foi utilizado $0,15 \mathrm{mg} /$ kg de xilasina via intramuscular (IM), 0,25 mg de atropina IM e $30 \mathrm{mg} / \mathrm{kg}$ de pentobarbital sódico a $3 \%$ via intraperitoneal (IP). Foi realizada uma dissecção venosa do membro torácico direito para manutenção anestésica, com pentobarbital sódico a 3\%, e para hidratação. Os procedimentos anestésicos foram registrados nos protocolos de anestesia dos procedimentos da operação inicial e da reoperação.

Todos os animais receberam $500 \mathrm{mg}$ de cefoxitina, via endovenosa (EV), 30 minutos antes da operação. Essa dose foi repetida 3 horas após a primeira.

Sob anestesia, a técnica operatória comum aos 3 grupos consistiu de: laparotomia mediana de aproximadamente 10 centímetros (cm) de extensão; identificação do íleo terminal, válvula ileocecal e ceco; dissecção do mesentério e do mesocólon, com ligadura e secção dos ramos das artérias e veias ileoceco-cólicas e mesentéricas craniais com fio de náilon preto trançado 00; ressecção da VIC com $10 \mathrm{~cm}$ de íleo terminal e $7 \mathrm{~cm}$ de cólon ascendente.

A técnica operatória específica para cada grupo consistiu de:

Grupo B: após a ressecção da VIC, fechou-se o coto do cólon em sutura contínua total com fio de polipropileno azul 4-0, seguida de uma segunda sutura na camada seromuscular, em pontos separados com fio de polipropileno azul 4-0. Para a dissecção da camada seromuscular do cólon, colocou-se um clamp intestinal neste, a $\pm 10 \mathrm{~cm}$ do coto suturado e injetouse solução fisiológica (SF) dentro lúmen deste segmento do cólon. Logo após, injetou-se SF entre as camadas seromuscular e mucosa do cólon a \pm 2 cm do coto suturado, a fim de causar o descolamento destas duas camadas. Em seguida, realizou-se uma incisão de $\pm 2 \mathrm{~cm}$ sobre esse local do cólon entre as camadas seromuscular e mucosa, e iniciou-se a dissecção dessas. Na medida em que foi descolada a camada seromuscular da mucosa, a primeira foi sendo incisada longitudinalmente em sua borda antimesentérica, até $\pm 7 \mathrm{~cm}$ de dissecção. A camada seromuscular foi descolada em aproximadamente 80\% da circunferência do cólon (Figura 1.A). Na extremidade caudal do segmento de cólon, realizouse uma incisão de $\pm 2 \mathrm{~cm}$ na mucosa para anastomose com o íleo terminal. Foi realizada uma anastomose ileocólica término-lateral, suturando-se todas as camadas do íleo terminal na mucosa do cólon, em pontos separados, com fio de polipropileno 4-0 (Figura 1.B). Em seguida, invaginou-se um segmento de $\pm 6 \mathrm{~cm}$ de íleo com a camada seromuscular do cólon, em pontos separados com fio de polipropileno 000 (Figura 2.A). A seguir, fixou-se o íleo terminal ao coto cranial do cólon em pontos separados seromusculares com fio de polipropileno 4-0.

Grupo C: após a ressecção da VIC, confeccionou-se uma anastomose ileocólica término- 
terminal em dois planos. Inicialmente, com uma sutura contínua, total, com fio de polipropileno 4-0, seguida de uma sutura seromuscular, em pontos separados, invaginando a primeira sutura, com o mesmo tipo de fio. Após os procedimentos específicos para cada grupo, realizou-se o fechamento do mesentério e do mesocólon em pontos separados com fio de polipropileno 4-0; fechamento do plano aponeurótico em sutura contínua ancorada e da pele, em pontos separados, com fio de náilon monofilamentar 000.
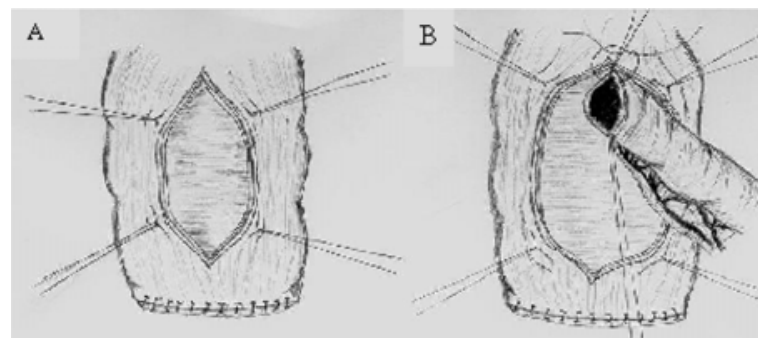

FIGURA 1: A) Cólon ascendente fechado terminalmente e camada seromuscular dissecada em $7 \mathrm{~cm}$ e descolada em $80 \%$ de sua circunferência. B) Anastomose entre a camada mucosa do cólon e o coto caudal do íleo.

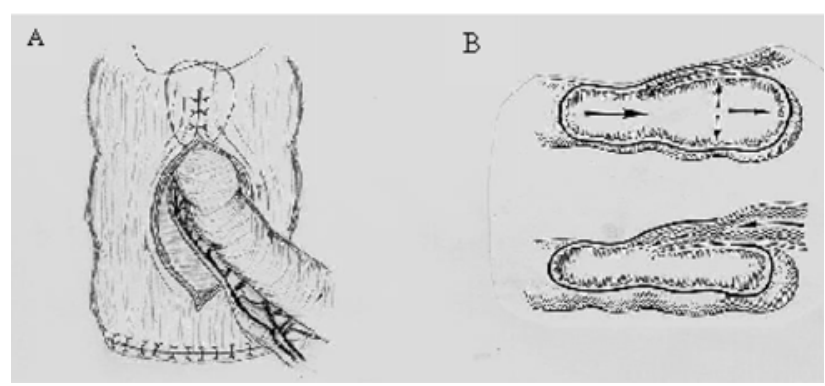

FIGURA 2: A) Fechamento da camada seromuscular criando um túnel submucoso. B) Visão lateral das fases fisiológicas da neoválvula ileocecal.

Após 45 dias de pós-operatório, os cães dos grupos B e C foram reoperados, sendo feito coleta de amostra do conteúdo intestinal para cultura e medição da pressão de refluxo colo-ileal. Também foi observado se havia distensão de íleo terminal, que indicaria obstrução intestinal no local da neoválvula ou da anastomose ileocólica término-terminal.

Grupo B: incisão de aproximadamente $10 \mathrm{~cm}$ sobre a cicatriz cirúrgica anterior e acesso à cavidade peritoneal; identificação da neoválvula ileocecal; ligadura e secção dos ramos das artérias e veias mesentéricas craniais e cólicas direitas; ressecção da neoválvula ileocecal. Imediatamente após a ressecção da neoválvula foi realizada a eutanásia.

Grupo C: incisão de aproximadamente $10 \mathrm{~cm}$ sobre a cicatriz cirúrgica anterior e acesso à cavidade peritoneal; identificação da anastomose ileocólica término-terminal; ligadura e secção dos ramos das artérias e veias mesentéricas craniais e cólicas direitas; ressecção da anastomose ileocólica término-terminal. Imediatamente após a ressecção da anastomose, foi realizada a eutanásia.

A eutanásia foi realizada com a injeção EV de $10 \mathrm{ml}$ de cloreto de potássio a 19,1\%, no animal ainda anestesiado.

Durante os 45 dias de pós-operatório, os cães foram observados clinicamente quanto ao peso, perímetro abdominal e evacuações. Também foram avaliadas as possíveis complicações como deiscência de sutura, infecção de parede abdominal e obstrução intestinal.

A análise microbiológica foi feita seguindo os procedimentos descritos por Myrvold e col. ${ }^{12}$. Colheu-se amostra para coprocultura, a $\pm 10 \mathrm{~cm}$ da VIC, em íleo terminal e em cólon, tanto na primeira operação (Grupo A) como na reoperação (Grupos $\mathrm{B}$ e C). As amostras foram coletadas injetando-se $\pm 2 \mathrm{~mL}$ de SF em um segmento de aproximadamente $2 \mathrm{~cm}$, nos locais acima citados. Após 1 minuto aspirou-se essa solução, que foi colocada em tubos estéreis para posterior semeadura em meios de cultura. Amostras com swab foram colhidas para inoculação em placas de Ágar.

Foram feitas culturas em Ágar sangue, a fim de se obter o número total de colônias e a flora bacteriana predominante e em meio MacConkey, para identificar bacilos gram-negativos, principalmente enterobactérias. A contagem total de colônias foi determinada pelo número de unidades formadoras de colônia por $\mathrm{mL}^{11}$. Foram analisadas apenas culturas de bactérias aeróbias. Essa análise bacteriológica foi feita pelo laboratório de microbiologia do Laboratório de Análises Clínicas do Hospital Universitário.

As medidas da pressão intracolônica, necessária para causar refluxo para o íleo, foram aferidas por um manômetro de coluna de água, confeccionado pela Engenharia Biomédica da UFSC. Este aparelho é constituído por um tubo de polietileno transparente, afixado em régua milimetrada, em forma semi-oval, tipo U, com 5 milímetros (mm) de diâmetro por 70 
cm de extensão total ${ }^{17,18}$.

Em um dos extremos do tubo foi conectado um cateter de nelaton 16 (primeira colotomia), que estava orientado para a luz colônica, referindo diretamente as alterações da pressão intracolônica. Outro cateter de nelaton 16 (segunda colotomia) foi conectado a um segundo tubo de polietileno transparente, com 3 mm de diâmetro por $100 \mathrm{~cm}$ de altura, tendo em sua extremidade superior um recipiente com a capacidade para armazenar $500 \mathrm{~mL}$ de SF com azul de metileno a $1 \%$, permitindo um fluxo contínuo de $400 \mathrm{~mL} /$ minuto $=2$ gotas/segundo (Figura 3 ) .

Esse manômetro foi elaborado a partir do

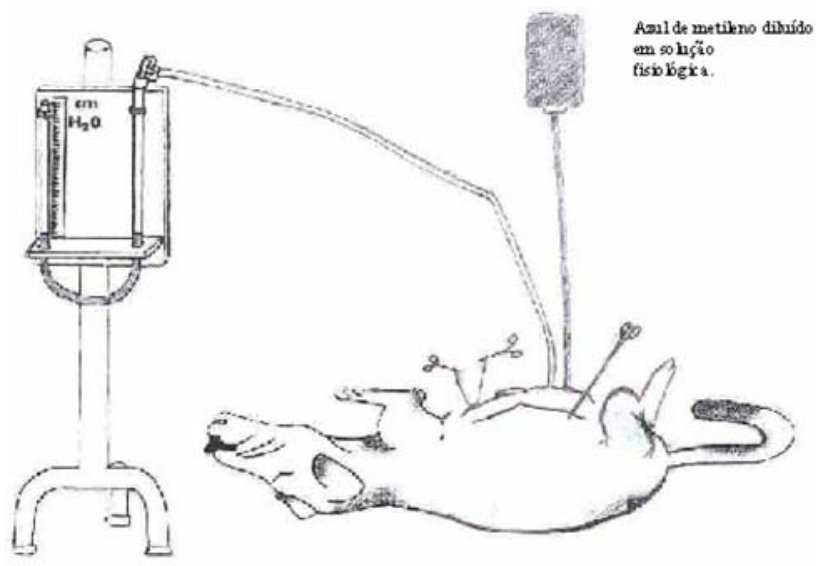

FIGURA 3: Demonstração do processo de medição do refluxo colo-ileal, evidenciando o manômetro de água, com as colunas de água e de azul de metileno e os cateteres colônicos. Modificado de Gieburowski ${ }^{17,18}$.

princípio físico da lei dos fluidos. Arelação da medida aferida neste manômetro, em cm, foi de $1 \mathrm{~cm}$ métrico/ $1,3 \mathrm{~cm}$ de água, pois nele atuaram o atrito das moléculas de água contra a parede do catéter, pressão atmosférica e umidade relativa do ar. O valor obtido no momento do refluxo do contraste do cólon para o íleo foi multiplicado por 2, pois ele refletiu a soma das duas colunas de água, ascendente e descendente, que compunham o manômetro.

No momento da aferição da pressão, foi necessária a atuação conjunta de 3 membros da equipe. $O$ primeiro cuidou do exato momento em que ocorreu o refluxo, pela visibilização da solução de azul de metileno no íleo terminal, por meio de uma abertura de $1 \mathrm{~cm}$ na borda anti-mesentérica do íleo, a 7 cm da VIC, neoválvula ou anastomose ileo-cólica.
O segundo cuidou da variação da coluna líquida na régua do manômetro. E o terceiro ocupou-se de controlar o fluxo contínuo da solução de azul de metileno ao cólon e de manter os cateteres desobstruídos.

Para a análise estatística foram utilizados testes não paramétricos, levando-se em consideração a natureza da variável estudada. Foram analisados os dados do peso, do diâmetro abdominal e da pressão de refluxo colo-ileal. Os testes utilizados foram: o teste de variância de Kruskal-Wallis, seguido do teste de Dunnns $^{19}$. O nível de significância mínimo foi de 5\%. Os cálculos e o gráfico foram feitos através do programa GraphPad Prism 3.0â.

As médias foram apresentadas a título ilustrativo e serviram para a confecção do gráfico.

\section{Resultados}

Clinicamente, os cães com neoválvula e os sem VIC evoluíram de modo semelhante. Ambos os grupos apresentaram, alternadamente, fezes diarréicas e pastosas durante todo pós-operatório. As medidas dos pesos inicial e final dos grupos com e sem VIC foram similares, sendo que não houve diferença estatística entre elas, $\mathrm{P}>0,05$ (Tabela 1).

TABELA 1 - Peso (kg) dos cães dos Grupos B(com neoválvula) e C (sem válvula ileocecal), antes e depois dos procedimentos operatórios.

\begin{tabular}{ccccc}
\hline & \multicolumn{2}{c}{ GRUPO B } & \multicolumn{2}{c}{ GRUPO C } \\
& INICIAL & FINAL & INICIAL & FINAL \\
\hline & 8,8 & 6,1 & 10,4 & 10,6 \\
& 9,0 & 8,0 & 8,8 & 6,8 \\
& 8,4 & 6,8 & 10,0 & 9,0 \\
& 9,0 & 8,9 & 9,4 & 7,0 \\
& 10,0 & 9,1 & 10,6 & 10,6 \\
& 7,2 & 7,9 & 8,5 & 8,0 \\
& 8,2 & 7,8 & 8,0 & 7,2 \\
\hline Média & $\mathbf{8 , 7}$ & $\mathbf{7 , 8}$ & $\mathbf{9 , 4}$ & $\mathbf{8 , 5}$ \\
\hline
\end{tabular}

Nenhum cão desenvolveu distensão abdominal e as medidas do diâmetro abdominal não apresentaram diferença significante entre elas, $\mathrm{P}>0,05$ (Tabela 2).

Em todos os animais reoperados, após 45 dias, tanto no grupo com neoválvula como no grupo sem válvula (anastomose íleo-cólica término-terminal), não 
foram encontradas alças intestinais distendidas, sugestivas de dificuldade de trânsito intestinal através da neoválvula ileocecal ou da anastomose ileo-cólica. Quanto às complicações, um cão apresentou deiscência da sutura da aponeurose do reto abdominal. Ele foi reoperado, sendo refeita a sutura, e apresentou boa evolução.

Quanto ao estudo bacteriológico, pesquisou-se apenas bactérias aeróbias e a predominante nas culturas de íleo e cólon foi Escherichia coli. Quantitativamente as culturas apresentaram um padrão de crescimento muito irregular, sendo que algumas culturas apresentaram crescimento tão intenso que não puderam ser quantificadas, enquanto outras não apresentaram crescimento.

Os cães com a VIC reconstruída apresentaram uma pressão de refluxo colo-ileal similar ao da VIC normal. Não houve diferença estatística entre estas pressões. $(\mathrm{P}>0,05)$. No entanto, estes grupos apresentaram uma pressão de refluxo significantemente maior em relação ao grupo sem válvula, sendo $\mathrm{P}<0,05$ para o grupo com válvula normal e $\mathrm{P}<0,001$ para o grupo com neoválvula (Tabela 3 e Figura 4).

TABELA 2 - Diâmetro abdominal (cm) dos cães dos Grupos B e C, antes e depois dos procedimentos operatórios.

\begin{tabular}{ccccc}
\hline & \multicolumn{2}{c}{ GRUPO B } & \multicolumn{2}{c}{ GRUPO C } \\
& INICIAL & FINAL & INICIAL & FINAL \\
\hline 45 & 36 & 48 & 48 \\
& 45 & 46 & 45 & 38 \\
& 42 & 38 & 47 & 46 \\
& 43 & 43 & 44 & 38 \\
& 43 & 40 & 46 & 45 \\
& 48 & 47 & 46 & 43 \\
\hline Média & 41 & 37 & 37 & 38 \\
\hline
\end{tabular}

TABELA 3 - Pressão de refluxo colo-ileal $\left(\mathrm{cmH}_{2} \mathrm{O}\right)$ em cães dos Grupos A, B e C

\begin{tabular}{cccc}
\hline GRUPOA & GRUPOB & GRUPOC \\
\hline & 18,6 & 27,3 & 2,60 \\
26,0 & 31,2 & 000 \\
20,8 & 24,7 & 000 \\
19,5 & 26,0 & 2,60 \\
26,0 & 22,1 & 2,60 \\
& 20,8 & 23,4 & 000 \\
& 24,7 & 23,4 & 000 \\
\hline Média & 22,3 & & \\
\hline
\end{tabular}

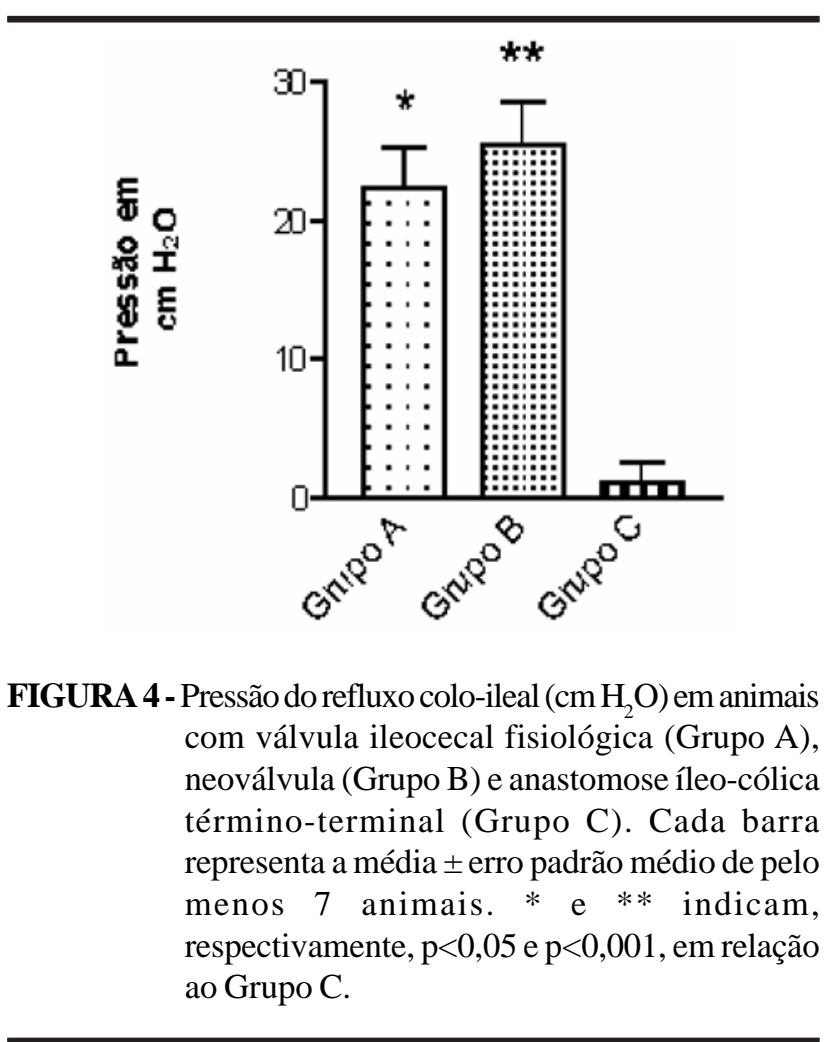

\section{Discussão}

A importância clínica e funcional da VIC tem sido relatada por vários estudos clínicos e experimentais 6,8,9,10,12,13. A colonização do intestino delgado por microorganismos do cólon, tem sido postulada como uma das causas da diarréia e da esteatorréia que ocorrem após as ressecções intestinais extensas ${ }^{6}$. Isso se deve, principalmente, à desconjugação de sais biliares e ácidos graxos causada por estes organismos $^{9}$. Glassman ${ }^{1}$ verificou em estudo experimental, um aumento do crescimento de bactérias aeróbias facultativas em íleo terminal, após a ressecção da VIC. Com a reconstrução dessa válvula, não houve diferença significante em relação à contagem bacteriana em animais normais. Por outro lado, Ricotta e col. ${ }^{14}$, também analisando bactérias aeróbias, não encontraram diferença significante na colonização do intestino delgado com ou sem reconstituição da VIC, após ressecção do segmento distal do íleo, incluindo a VIC. Esses autores encontraram como bactéria aeróbia predominante, na flora de íleo e cólon, a Escherichia coli.

No presente estudo, realizou-se apenas a análise de bactérias aeróbias. A bactéria predominante também foi a Escherichia coli, conforme a literatura. Não foi possível detectar uma bactéria (aeróbia) que predominasse na flora do cólon, e que permitisse 
avaliar a continência da neoválvula, conforme seu crescimento em íleo terminal. A análise quantitativa não forneceu dados consistentes que pudessem servir para comparação entre o crescimento bacteriano em íleo terminal na presença da VIC normal (Grupo A), com o crescimento encontrado após 45 dias da reconstrução da neoválvula (Grupo B) ou da anastomose ileocólica simples (Grupo C). Esses fatos mostraram a dificuldade em se avaliar a continência de substitutos da VIC pela análise de culturas de bactérias aeróbias, fato também relatado por Ricotta e col. ${ }^{14}$.

Myrvold e col. ${ }^{12}$ estudaram a eficácia de uma técnica de reconstituição da VIC em prevenir a colonização bacteriana do intestino delgado pela flora colônica. Eles referiram, após a ressecção da VIC, que pela contagem de bactérias anaeróbias não havia diferença significativa entre o íleo terminal e o cólon, nos cães sem VIC. Entretanto, com a reconstrução da VIC, houve uma queda significante no número de bactérias anaeróbias em íleo terminal quando comparado ao cólon. Esses resultados sugeriram que as bactérias anaeróbias predominam no cólon e são encontradas em menor número no intestino delgado. Portanto, a presença de um aumento do crescimento de bactérias anaeróbias em íleo terminal indicaria a ocorrência do refluxo colônico. Dessa maneira, estes autores sugeriram que a análise quantitativa das bactérias seria um bom indicador da continência de um substituto da VIC. Kholoussy e col. ${ }^{7}$, assim como Richardson e Griffen ${ }^{8}$, estudando outras técnicas de reconstituição da VIC como barreira bacteriológica e analisando bactérias anaeróbias, chegaram a resultados semelhantes.

Com os resultados encontrados na literatura, principalmente os trabalhos de Richardson e Griffen ${ }^{8}$, Myrvold e col. ${ }^{12}$ e Kholoussy e col. ${ }^{7}$, a análise de bactérias anaeróbias para avaliar as técnicas de reconstituição da VIC como barreira bacteriológica, mostrou-se ser um método melhor e de maior reprodutibilidade que a análise de bactérias aeróbias.

Neste estudo não se realizou a avaliação microbiológica de bactérias anaeróbias devido ao alto custo e à impossibilidade técnica do laboratório de Análises Clínicas da UFSC, em realizar esse procedimento.

Kholoussy e $\operatorname{col}^{7}$, estudando outra técnica de reconstituição da VIC, verificaram que não houve diferença entre o grupo com e sem VIC, após um período de acompanhamento clínico de 16 semanas, em que se avaliou evacuações e perda de peso. Singleton e col. ${ }^{4}$ observaram que a perda de peso entre o grupo sem VIC e outro com um segmento intestinal invertido $(9,5 \mathrm{~cm})$ foi similar. Thompson e col. ${ }^{21}$ verificaram que não havia diferença significativa entre a perda de peso, após 12 semanas, entre os grupos de cães com ressecção do intestino delgado (50\% de extensão) com VIC preservada e os cães com a mesma ressecção, porém sem VIC.

No presente estudo, levando-se em conta o peso, o perímetro abdominal e as evacuações não houve diferença na evolução clínica dos grupos com e sem reconstituição da VIC. Quanto ao peso, apesar de ter ocorrido perda de peso durante o período de pósoperatório, tanto no grupo com neoválvula como no grupo sem VIC, as medidas do peso inicial e final desses grupos, não apresentaram diferença significante $(\mathrm{P}=0,145)$. Portanto, a perda ponderal para os dois grupos não foi importante. Nenhum cão apresentou distensão abdominal durante o pós-operatório, sendo que as medidas do diâmetro abdominal inicial e final foram similares entre os cães dos grupos com neoválvula e sem VIC $(\mathrm{P}=0,353)$. Quanto às evacuações, todos os animais evoluíram com fezes diarréicas a pastosas. Esses resultados poderiam estar relacionados ao tempo decorrido entre a primeira operação e a reoperação, que pode não ter sido suficiente para adaptação dos animais às alterações anatômicas e fisiológicas de seu trato gastrintestinal. Sugere-se, deste modo, que talvez um tempo mais longo de observação fosse necessário para se obter uma melhor avaliação clínica. Poucos dos autores pesquisados descreveram a evolução clínica dos animais durante seus estudos, o que dificultou o estabelecimento de um período adequado para este tipo de avaliação ${ }^{4,7,20}$.

Hofmann e col. ${ }^{21}$, estudando a pressão da VIC em cães, com um transdutor de pressão (Gould Statham P50), encontraram uma pressão média de $26,4 \pm 2,2 \mathrm{~cm} \mathrm{H}_{2} \mathrm{O}$. Já, Quigley et $\mathrm{al}^{23}$, usando um transdutor de pressão (Bentley Trantec model 800), registraram pressões entre $31 \pm 18 \mathrm{~cm} \mathrm{H}_{2} \mathrm{O}$. Por outro lado, Rendleman e col. ${ }^{3}$, também estudando a pressão da VIC em cães, com um manômetro de água, obtiveram pressões de refluxo que variavam desde completa incontinência até a $28 \mathrm{~cm} \mathrm{H}_{2} \mathrm{O}$. Com esses dados, tem sido sugerido que, apesar de algumas variações, a VIC possuiria uma pressão basal 
que lhe conferiria uma função esfincteriana, prevenindo o refluxo do conteúdo colônico para o íleo terminal ${ }^{3,21,22}$.

Os resultados desse estudo, com a avaliação manométrica, mostraram que essa técnica de reconstituição da VIC apresentou uma pressão de refluxo colo-ileal similar ao da VIC fisiológica, sem apresentar diferença significante entre elas $(\mathrm{P}>0,05)$. As medidas dessas pressões variaram de 18,6 a 26,0 $\mathrm{cm} \mathrm{H}_{2} \mathrm{O}$ para VIC fisiológica e de 22,1 a 31,2 cm $\mathrm{H}_{2} \mathrm{O}$ para neoválvula, sendo as médias 22,3 e 25,4 $\mathrm{cm} \mathrm{H}_{2} \mathrm{O}$, respectivamente. A variação entre as pressões de refluxo colo-ileal dentro de cada grupo foi muito pequena, sem apresentar significância. Portanto, isso sugere que esse manômetro de água foi um método eficaz e confiável na avaliação da VIC e seus substitutos, como barreiras ao refluxo coloileal. As pressões de refluxo, tanto do grupo com VIC fisiológica como do grupo com neoválvula, foram significantemente maiores que as pressões do grupo sem VIC, com $\mathrm{P}<0,05$ e $\mathrm{P}<0,001$, respectivamente. Esses achados sugeriram que essa técnica de reconstituição da VIC, foi eficaz em prevenir o refluxo colônico de modo similar a VIC normal, sem apresentar complicações como obstrução e isquemia intestinais.

Uma vez que essas medidas das pressões de refluxo colo-ileal foram obtidas utilizando-se SF, pode-se sugerir que o obstáculo seria maior ao conteúdo normal do cólon, por sua maior viscosidade.

\section{Conclusão}

A neoválvula ileocecal é um obstáculo ao refluxo colo-ileal em cães.

\section{Referências}

1. Glassman JA. An artificial ileocecal valve. Surg Gynecol Obstet. 1942; 74:92-8.

2. Kellogg JH. Surgery of the ileocecal valve. Surg Gynecol Obstet. 1913; 17:563-76.

3. Rendleman DF, Anthony JE, Davis C, Buenger RE, Brooks AJ, Beattie EJ. Reflux pressure studies on the ileocecal valve of dogs and humans. Surgery. 1958; 44:640-3.

4. Singleton AO, Redmond DC, McMurray J. Ileocecal ressection and small bowel transit and absorption. Ann Surg. 1964; 159:690-4.

5. Fisch M, Wammack R, Spies F, Müller SC, Mokthar A, Ghoneim M, Hohenfellner R. Ileocecal valve reconstruction during continent urinary diversion. J Urol. 1994; 151:861-5.

6. Gazet JC, Kopp J. The surgical significance of the ileocecal junction. Surgery. 1964; 151:861-5.

7. Kholoussy MA, Yang Y, Bonacquisti K, Witkowski T, Takenaka K, Matsumoto T. The competence and bacteriologic effect of telescoped intestinal valve after small bowell ressection. Am Surg. 1986; 52:555-9.

8. Richardson DJ, Griffen WO. Ileocecal valve substitutes as bacteriologic barriers. Am J Surg. 1972; 123:149-53.

9. Weser E, The management of patients after small bowel ressection. Gastroenterology. 1976; 71:146-50.

10. Kaufman SS, Loseke CA, Lupo JV, Young RJ, Murray ND, Pinch LW, Vanderhoof JA. Influence of bacterial overgrowth and intestinal inflamation on duration of parenteral nutrition in children with short bowel syndrome. J Pediatr. 1997; 131 (3):356-61.

11. Vinograd I, Merguerian P, Udassin R, Mogle P, Nissan S. An experimental model of a submucosally tunelled valve for the replacement of the ileocecal valve. J Pediatr Surg. 1984; 19:726-31.

12. Myrvold H, Jindel MS, Isenberg HD, Stein TA, Scherer J, Wise L. The Nipple Valve as a sphincter substitute for the Ileocecal Valve: Prevention of bacterial overgrowth in the small bowel. Surgery. 1994; 96(1):42-7.

13.Chardavoyne R, Isenberg HD, Tindel M, Stein TA, Scherer TS, Wise L. Microbiologic Efficacy of a Surgically Constructed Nipple Valve. Am J Surg. 1984; 147(2):230-3.

14. Ricotta J, Zuidema GD, Gadacz TR, Sadri D. Construction of an ileocecal valve and its role in massive ressection of the small intestine. Surg Gynecol Obstet. 1981; 152:310-4.

15. Schiller WRP, Didio LJA, Anderson MC. Production of artificial sphincters. Arch Surg. 1967; 95:436-42.

16. Stacchini A, Didio LJA, Primo MLS, Borelli V, Andretto R. Artificial sphincters as surgical treatment for experimental massive ressection of small intestines. Am J Surg. 1982; 143:721-6.

17. Gieburowski JRL. Cirurgia de Thal-Hatafuku: Modelo experimental de análise funcional e histológica [dissertação de mestrado]. Rio de Janeiro (RJ): Universidade Federal do Rio de Janeiro; 1998.

18. Gieburowski JRL, Acampora AJ, Silva, MH, Chaves CP, Fortuna MB. Modelo experimental de análise funcional e histológica. Rev Col Bras Cir. 2000, 26:351.

19. Siegel S, Castellan JrNJ. Nonparametrics statistics. 2.ed. New York: Mc Graw-Hill Int.; 1988.

20. Thompson JS, Quigley EM, Palmer JM, West WW, Adrian TE. Lumial short-chain fatty acids and postsection intestinal adaptation. JPEN. 1996; 20 (5):338-43.

21. Hofmann R, Gomes R, Tanagho EA, McAninch JW, Stoller ML. Stimulated pressure response of the ileocolonic junctional zone and its use as a continence mechanism in a canine model. Urol Res. 1993; 21(5): 333-7.

22. Quigley EM, Phillips SF, Dent J, Taylor BM. Myoeletric activity and intraluminal pressure of the canine ileocolonic sphincter. Gastroenterology. 1983; 85:1054-62. 
Correspondência:

Felipe Antonio Boff Maegawa

R. Tenente Silveira, 514/1005

88010-300 Florianópolis - SC

fboffmaegawa@hotmail.com
Conflito de interesse: nenhum Fonte de financiamento: nenhuma

Recebimento: 11/10/2004

Revisão: 10/11/2004

Aprovação: 06/12/2004

\section{Como citar este artigo:}

Maegawa FAB, Souza JÁ, Araújo EJ, Koh IHJ, d’Acampora AJ, Farias DC, Mengarda J, Volpato D, Silva LGF, Córdova CS. Reconstituição da válvula ileocecal em cães. Acta Cir Bras. [serial online] 2005 Jan-Fev;20(1). Disponível em URL: http://www.scielo.br/acb 